\title{
THE INFLUENCE OF FORM AND MATERIALS ON THE PROPER ACOUSTIC FUNCTION OF THEATRICAL PERFORMANCES AND MUSIC CONCERTS AT GEDUNG KESENIAN IN JAKARTA
}

\author{
${ }^{1}$ Susanti Mega. ${ }^{2}$ Ir. E. B. Handoko Susanto, M.T. \\ ${ }^{1}$ Student in the Bachelor's (S-1) Study Program in Architecture \\ at Parahyangan Catholic University \\ ${ }^{2}$ Senior lecturer in the Bachelor's (S-1) Study Program in Architecture \\ at Parahyangan Catholic University
}

\begin{abstract}
A given space requires a specific design for it to function in the best possible way. Many aspects need to be taken into consideration, and the same principle applies to an auditorium. Its space requires proper handling of the right acoustics to optimize the activities to be held there, among others space employed for the purpose of staging theatrical performances and concerts. Ideally speaking, these activities must prioritize the use of natural (purely acoustic) sound without resorting to an electric amplifier. Therefore, an appropriate acoustic design of the space to be used is of the utmost necessity. Each of these spaces has its own criteria to optimize the activities that are held there. To examine the acoustic quality of a given space, there are several prerequisites that must be fulfilled, starting from the form and materials used, the sound's volume level, sound distribution, reverberation time, acoustic flaws or shortcomings and noise reduction or sound control. Using the explorative method and post-performance evaluation, this research study investigates the capability of the Arts Building called Gedung Kesenian in Jakarta to accommodate two different activities, both from the angle of the specific activity and the prerequisites for the space used. Gedung Kesenian Jakarta has attempted to surmount the problem of echo/reverb that is different for the theatrical and musical performances. However, the too widely diverging values have prompted the need for adding portable elements that are passive in nature in order to maximize the sound reflection, evenness of sound distribution, reverb time as well as dealing with the problem of the echoing sound area, referred to as "shadow sound".
\end{abstract}

Keywords: acoustic suitability, acoustics of theater space, acoustics of concert space, reverberation time

\section{PENGARUH BENTUK DAN MATERIAL TERHADAP KELAYAKAN AKUSTIK FUNGSI TEATER DAN KONSER PADA GEDUNG KESENIAN JAKARTA}

\author{
${ }^{1}$ Susanti Mega. ${ }^{2}$ Ir. E. B. Handoko Susanto, M.T. \\ ${ }^{1}$ Mahasiswa S1 Program Studi Arsitektur Universitas Katolik Parahyangan. \\ 2 Dosen Pembimbing S1 Program Studi Arsitektur Universitas Katolik Parahyangan.
}

\begin{abstract}
Abstrak- Sebuah ruang membutuhkan desain secara spesifik agar dapat berfungsi secara maksimal. Banyak aspek yang perlu dipertimbangkan dan hal tersebut berlaku pula pada auditorium. Sebuah ruang auditorium membutuhkan penanganan akustik yang baik untuk mengoptimalkan aktivitas yang berlangsung dalam ruang, di antaranya untuk ruang teater juga ruang konser. Aktivitas teater dan konser idealnya harus memprioritaskan
\end{abstract}

\footnotetext{
${ }^{1}$ Corresponding author: susanti.mega@hotmail.com
} 
penggunaan suara alami, tanpa menggunakan bantuan pengeras suara. Oleh karena itu perancangan akustik ruang yang tepat sangatlah dibutuhkan. Masing-masing ruang tersebut memiliki kriterianya sendiri untuk dapat mengoptimalkan aktivitas yang berlangsung di dalamnya. Untuk mengkaji kualitas akustik ruang terdapat beberapa syarat yang harus dipenuhi mulai dari bentuk dan material, tingkat kekerasan suara, penyebaran suara, waktu dengung, cacat akustik serta pengendalian bising. Dengan metode eksploratif dan evaluasi pascahuni, penelitian ini mengkaji kemampuan Gedung Kesenian Jakarta dalam menampung dua aktivitas yang berbeda baik dari segi kegiatan maupun persyaratan ruangnya. Gedung Kesenian Jakarta berusaha menyelesaikan permasalahan terkait waktu dengung yang berbeda antara aktivitas teater dan konser. Namun perbedaan nilai yang terlalu jauh membuat auditorium tersebut membutuhkan tambahan elemen portabel yang bersifat pasif guna memaksimalkan pemantulan bunyi, kemerataan penyebaran bunyi, waktu dengung, serta mengatasi area bayangan bunyi.

Kata Kunci: kelayakan akustik, akustik ruang teater, akustik ruang konser, waktu dengung

\section{PENDAHULUAN}

Gedung Kesenian Jakarta merupakan sebuah auditorium yang pada awalnya difungsikan sebagai ruang teater sebagai jawaban atas kebutuhan masyarakat akan hiburan. Namun seiring dengan berjalannya waktu, konser musik klasik semakin berkembang di Indonesia dan dipaksakan untuk diselenggarakan dalam ruang yang sama.

Pada dasarnya aktivitas teater dan konser musik memiliki kriteria spesifik yang harus dipernuhi dalam perancangan ruang akustik. Nilai waktu dengung yang cukup jauh membuat keduanya tidak dapat ditempatkan dalam ruangan yang sama. Padahal waktu dengung merupakan elemen mendasar yang harus dipenuhi demi mengoptimalkan kenyamanan akustik auditorium. Ruang teater membutuhkan nilai waktu dengung yang pendek agar kata-kata yang diucapkan terdengar lebih jelas dan tidak saling menumpuk sedangkan ruang konser membutuhkan nilai waktu dengung yang panjang agar melodi musik terdengar lebih mengalun.

Kondisi tersebut menyebabkan ruang auditorium GKJ membutuhkan pengkondisian khusus agar kedua fungsi dapat diakomodasi dengan maksimal. Desain ruang terkait bentuk dan material yang digunakan akan sangat mempengaruhi kenyamanan akustiknya.

Penelitian ini bertujuan untuk menganalisa apakah Gedung Kesenian Jakarta dapat mengakomodasi fungsi teater dan konser musik sekaligus serta pengaruh bentuk dan material terhadap upaya untuk mengakomodasi kedua fungsi tersebut.

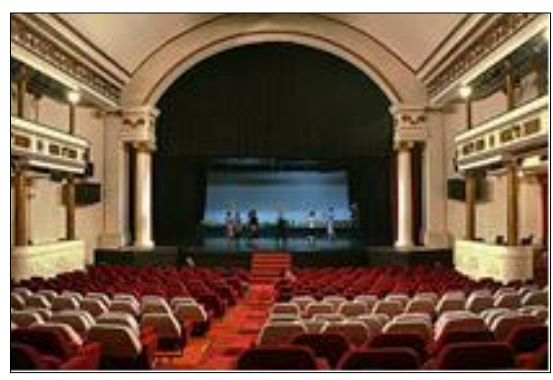

Figur 1. Area panggung auditórium

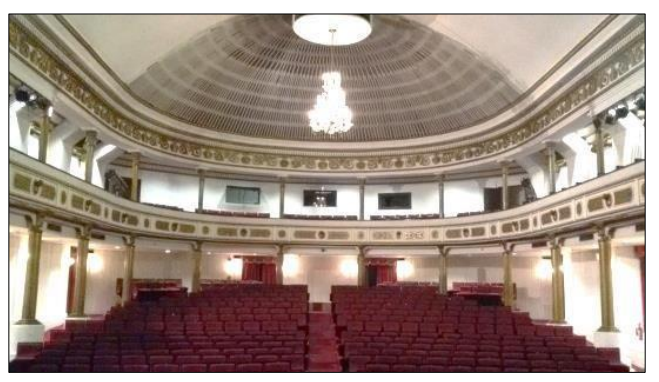

Figur 2. Area penonton auditórium

\section{KAJIAN TEORI}

\subsection{FUNGSI RUANG}

Fungsi teater dan konser yang dilaksanakan dalam auditorium GKJ membutuhkan penyikapan yang berbeda untuk memaksimalkan kenyamanan akustiknya. Terdapat dua 
perbedaan mendasar yang membuat kedua fungsi membutuhkan desain spesifik terkait bentuk dan material yang digunakan.

\subsubsection{FOKUS}

Aktivitas konser menitikberatkan perhatiannya pada aspek audial. Dengan memaksimalkan kualitas pendengaran, penonton dapat menghayati konser secara menyeluruh. Berbeda dengan aktivitas teater yang membutuhkan baik aspek visual maupun audial. Kenyamanan penonton dalam melihat pementas di atas panggung akan mengoptimalkan proses pendengaran dan pemahaman jalan cerita

\subsubsection{WAKTU DENGUNG}

Waktu dengung merupakan aspek yang terkait dalam desain auditorium karena aktivitas yang berbeda akan membutuhkan nilai waktu dengung yang berbeda untuk mengoptimalkan kenyamanan audialnya. Untuk aktivitas teater dibutuhkan waktu dengung pendek agar tidak menimbulkan penumpukan pendengaran kosa kata sedangkan aktivitas konser membutuhkan waktu dengung panjang agar alunan melodi terdengar halus dan mengalun.

\section{ANALISIS}

\subsection{BENTUK RUANG DALAM ARSITEKTUR}

\subsubsection{DIMENSI}

Auditorium GKJ memiliki dimensi-dimensi ruang yang sudah memenuhi kriteria desain baik untuk aktivitas teater maupun konser seperti dimensi panggung, jarak terdekat dan terjauh sumber bunyi ke penonton, kemiringan posisi tempat duduk penonton, juga area sirkulasi. Namun volume ruang $7052 \mathrm{~m}^{3}$ terlalu besar untuk kedua fungsi yang diakomodasi di dalamnya dimana volume ruang ideal untuk GKJ berdasarkan perhitungan adalah 1913.5 $\mathrm{m}^{3}$ sehingga perlu penyesuaian lebih lanjut untuk mengatasi masalah yang timbul terkait waktu dengung dan pendistribusian bunyi.

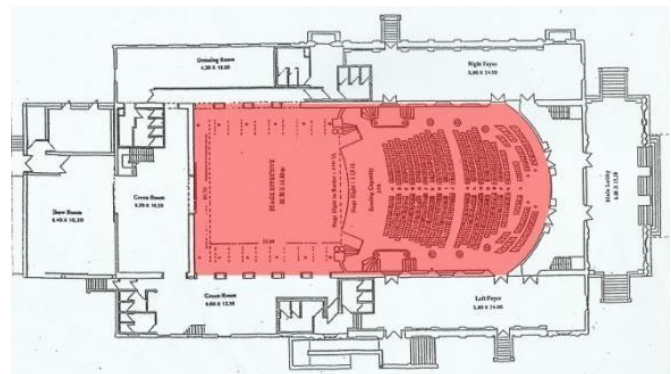

Figur 3. Bentuk ruang Gedung Kesenian Jakarta

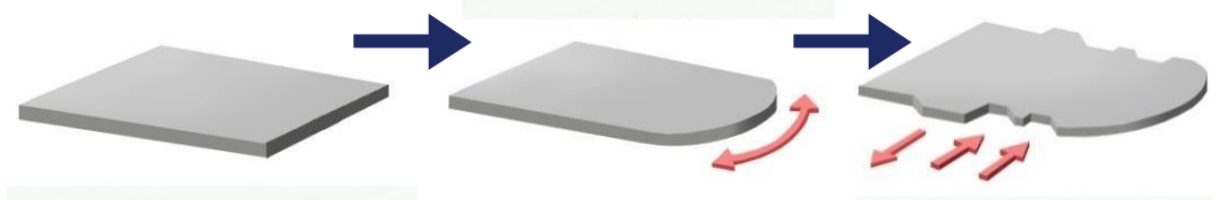

Figur 4. Proses perancangan bentuk auditorium GKJ 


\subsubsection{TEKSTUR}

Tekstur dalam auditorium GKJ banyak ditemukan pada kolom serta dinding balkon. Keduanya dapat dimanfaatkan untuk memaksimalkan pendifusian bunyi guna menyebarkan bunyi ke setiap bagian ruangan.

\subsubsection{POSISI DAN ORIENTASI}

Auditorium GKJ memiliki 3 jalur sirkulasi dimana salah satunya adalah sirkulasi tengah yang merupakan area penyebaran bunyi paling maksimal. Akan tetapi sirkulasi tersebut dibutuhkan untuk meningkatkan interaksi antara pementas dan penonton sehingga penyesuaian dilakukan demi terpenuhinya aspek fungsional aktivitas yang dilaksanakan.

Selain itu hal krusial terkait posisi elemen interior adalah kolom-kolom yang ditempatkan di sisi kiri dan kanan penonton guna menopang struktur balkon. Akan tetapi perencanaan yang baik justru membuat kolom-kolom tersebut mendukung proses pendifusian bunyi dalam ruang.

\subsection{PERSYARATAN AKUSTIK RUANG}

\subsubsection{AKUSTIK RUANG TEATER}

Teater merupakan gedung atau ruangan tempat pertunjukan film, sandiwara, dan sebagainya. Oleh karena itu dapat diketahui bahwa teater menitikberatkan aktivitasnya pada kegiatan pidato sehingga inteligibilitas suara harus diutamakan agar penonton dapat menangkap setiap kata dan memahami jalan cerita yang dipentaskan. Pada aktivitas teater, hubungan antara pementas dan penonton baik audial maupun visual harus diutamakan karena keduanya saling mendukung untuk menciptakan pemahaman yang maksimal akan jalan cerita yang dipentaskan.

Dari segi waktu dengung sebuah ruang teater membutuhkan waktu dengung yang pendek agar setiap kata yang diucapkan oleh pementas dapat terdengar degan bersih dan jelas tanpa adanya penumpukan kosa kata. Hal ini sangat berpengaruh dalam mengoptimalkan pemahaman jalan cerita oleh penonton.

\subsubsection{AKUSTIK RUANG KONSER}

Konser diartikan sebagai pertunjukan musik di depan umum. Oleh karena itu dapat dilihat bahwa elemen musik serta kenyamanan audial merupakan titik berat yang menjadi fokus utama dalam perancangan sebuah ruang konser.

Selain itu terdapat beberapa aspek psikis yang turut menentukan keberhasilan perancangan sebuah ruang konser yaitu keakraban (intimacy), kejelasan (clarity), keseimbangan (balance), pencampuran (blend), serta kesatuan (ensemble).

Sedangkan dari segi waktu dengung, sebuah ruang konser membutuhkan waktu dengung yang panjang karena bunyi musik harus mengalun lebih panjang dari suku kata pembicaraan. Selain itu kekaburan dan tumpang tindih dalam alunan musik justru diinginkan untuk keindahan alunan nada.

\subsection{MATERIAL AKUSTIK}

\subsubsection{MATERIAL PEMANTUL BUNYI}

Material yang memiliki nilai koefisien absorbsi kurang dari 0.2 ini banyak dimanfaatkan di area panggung dan area samping penonton untuk memaksimalkan pemantulan bunyi dari sumber bunyi di atas panggung 


\subsubsection{PARKET KAYU}

Material dengan koefisien absorbsi 0.07 ini menutupi seluruh area lantai panggung dan efektif untuk pemantulan bunyi dikarenakan bagian dalamnya tersusun dari plat beton yang masif.

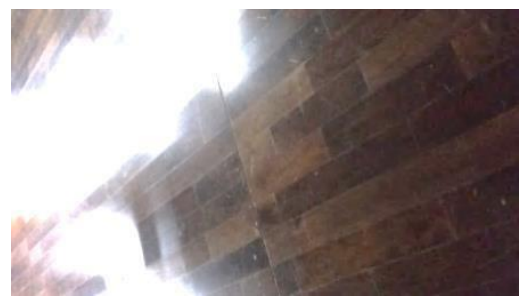

Figur 5. Parket kayu

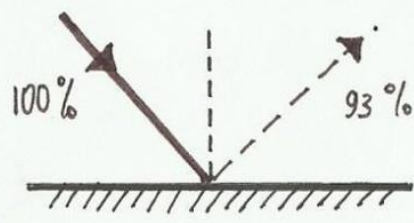

Figur 6. Pemantulan bunyi pada parket kayu

\subsubsection{PANEL KAYU}

Panel kayu merupakan pembatas antara panggung dengan ruang persiapan yang diposisikan miring menghadap penonton. Hal ini dimaksudkan untuk memaksimalkan pemantulan bunyi ke arah penonton.

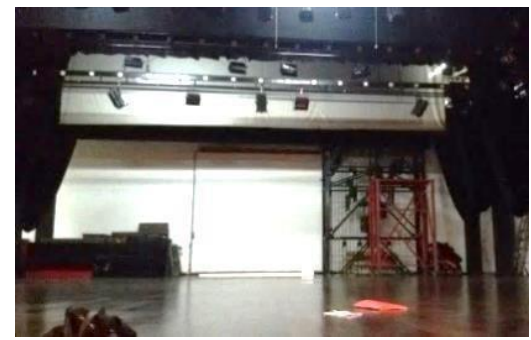

Figur 7. Panel kayu belakang panggung

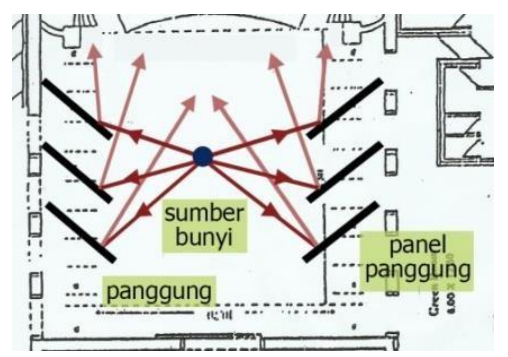

Figur 8. Pemantulan bunyi pada panel kayu

\subsubsection{DINDING BETON}

Material beton pada pedestal kolom yang memiliki permukaan cembung sangat efektif dalam memantulkan bunyi ke segala arah. Pedestal ini diposisikan di area samping penonton bagian depan untuk mengoptimalkan pemantulan bunyi dari area panggung.

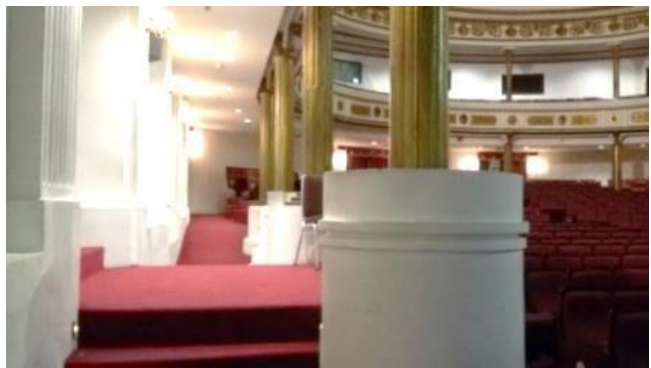

Figur 9. Pedestal kolom beton

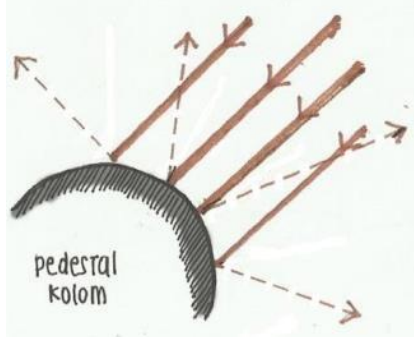

Figur 10. Pemantulan bunyi pada pedestal kolom

\subsubsection{MATERIAL PENYERAP BUNYI}

Material penyerap bunyi banyak dimanfaatkan sebagai penutup area lantai dan beberapa bagian dinding

\subsubsection{KARPET TEBAL}


Karpet tebal digunakan untuk melapisi seluruh area penonton guna meredam suara langkah kaki penonton yang berlalu lalang.

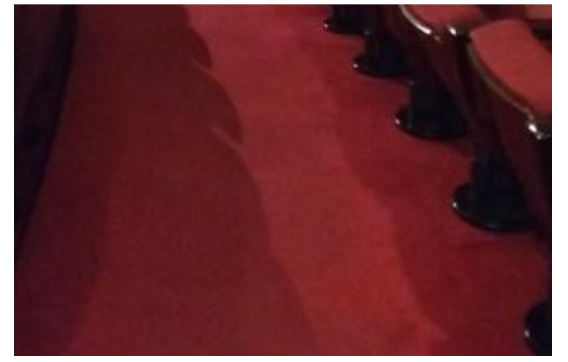

Figur 11. Karpet tebal penutup lantai

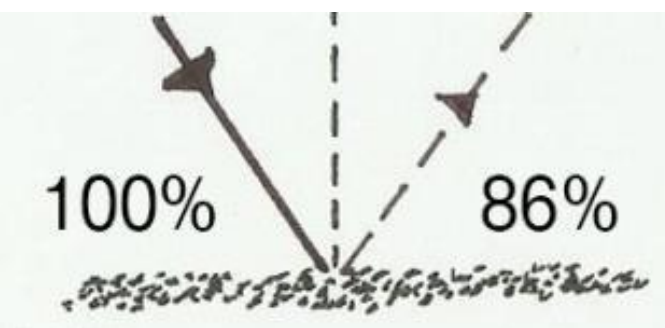

Figur 12. Pemantulan bunyi pada karpet tebal

\subsubsection{KARPET TIPIS}

Karpet tipis digunakan untuk melapisi tangga movable agar tetap dapat meredam langkah kaki pementas namun tetap ringan untuk dipindahkan.

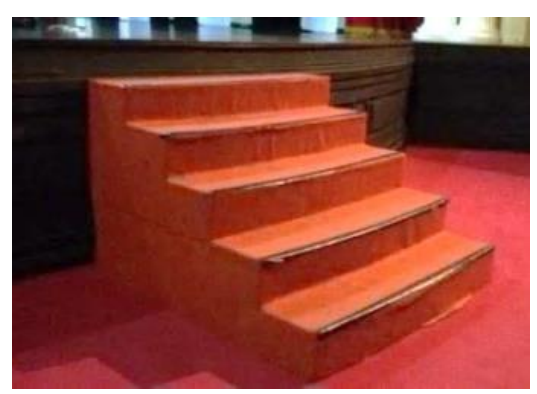

Figur 13. Karpet tipis penutup tangga

\subsubsection{TIRAI}

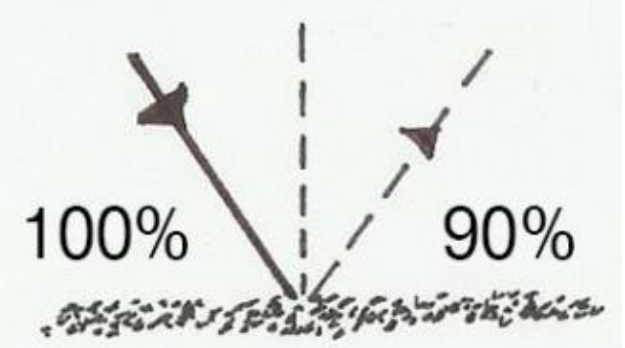

Figur 14. Pemantulan bunyi pada karpet tipis 
Tirai tebal yang diposisikan di beberapa area dinding berfungsi menyerap suara dengan tujuan memperkecil waktu dengung ruangan. Hal tersebut dimaksudkan agar pelafalan katakata pada aktivitas teater terdengar jelas.

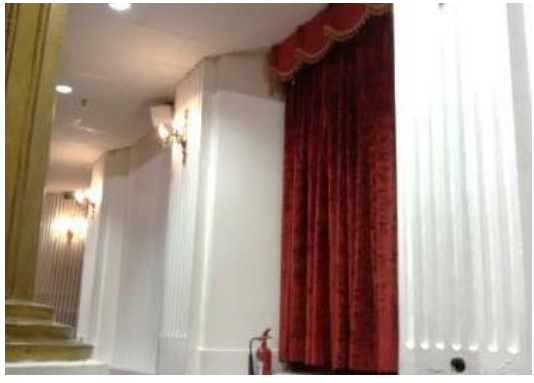

Figur 15. Tirai pada dinding

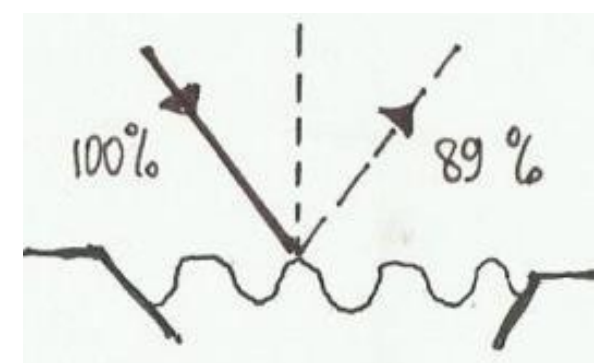

Figur 16. Penyerapan bunyi pada tirai

\subsubsection{KURSI SINEMA}

Kursi sinema yang memiliki koefisien absorbsi 0.8 ini secara otomatis melipat apabila tidak digunakan menggunakan material yang tebal dan empuk sehingga efektif untuk menyerap suara.

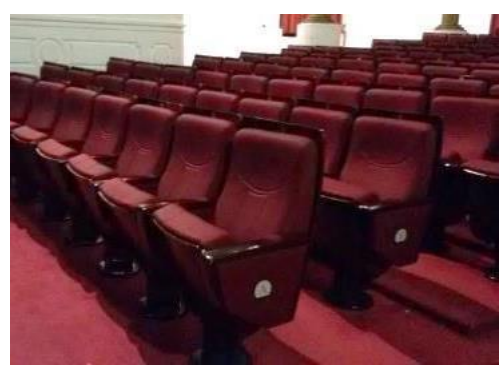

Figur 17. Kursi sinema

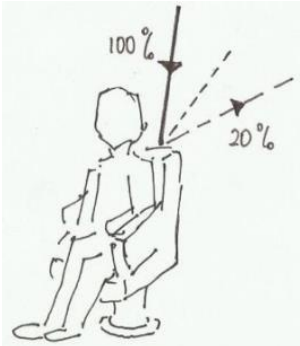

Figur 18. Penyerapan bunyi oleh kursi sinema

\subsubsection{MATERIAL PENDIFUSI BUNYI}

Pada auditorium GKJ material ini diposisikan di dinding dan plafond untuk menyebarkan bunyi ke segala arah

\subsubsection{AREA LANTAI}

Kaki kursi sinema terbuat dari besi yang berlubang-lubang sehingga efektif untuk proses pendifusian bunyi.

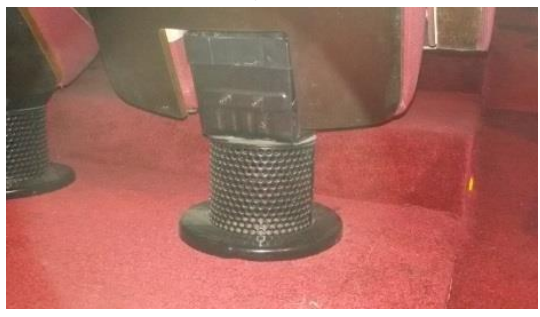

Figur 19. Kaki kursi sinema

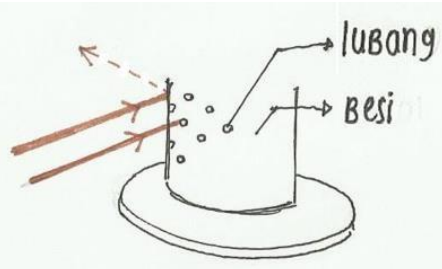

Figur 20. Perilaku bunyi pada kaki kursi sinema

\subsubsection{AREA DINDING}

Dinding auditorium GKJ tersusun dari rangka kayu yang dipasang berselang-seling dengan material kasa sehingga sangat efektif untuk mendifusikan bunyi. Selain itu kolom yang berlekuk-lekuk juga turut menyebarkan bunyi ke segala bagian ruang. 


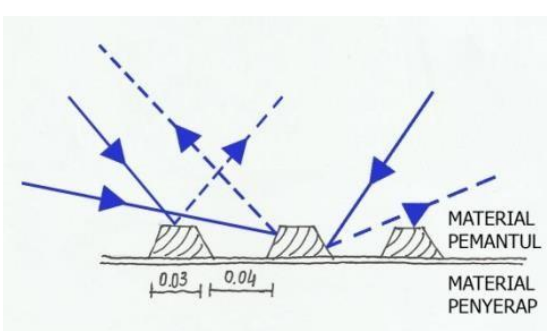

Figur 21. Pendifusian bunyi pada material dinding

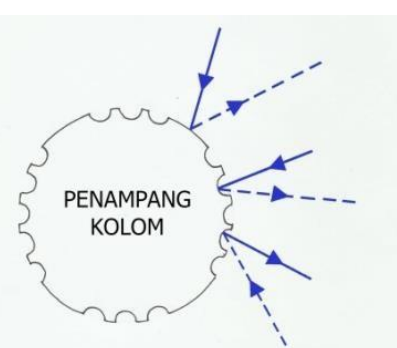

Figur 22. Pendifusian bunyi pada kolom auditórium

\subsubsection{AREA PLAFOND}

Pemanfaatan diffuser pada plafond bagian belakang sangat berperan dalam meghilangkan kemungkinan pemusatan bunyi akibat penggunaan plafond cekung. Selain itu material yang disusun maju dan mundur ini juga sangat efektif dalam menyebarkan bunyi ke segala arah.

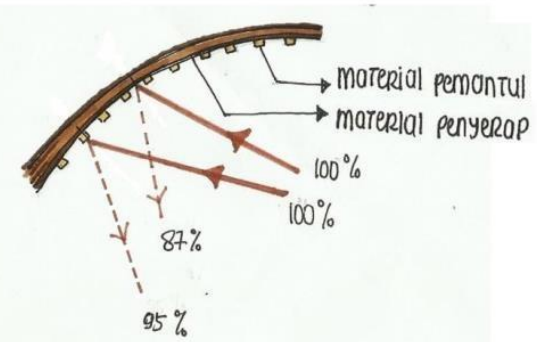

Figur 23. Pendifusian bunyi pada plafond cekung

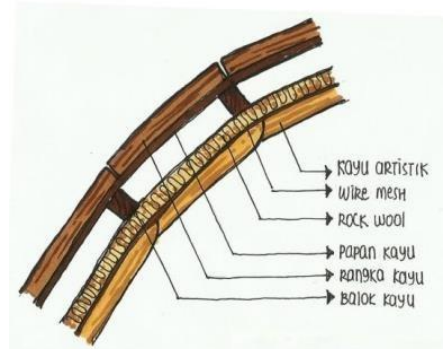

Figur 24. Potongan material pendifusi bunyi plafond

\subsection{KUALITAS AKUSTIK RUANG}

Proses analisa kelayakan kualitas akustik ruang didasarkan pada lima aspek yaitu:

\subsubsection{Kekerasan suara yang cukup}

Tingkat kekerasan bunyi dalam ruang diukur menggunakan sound level meter pada sepuluh titik yang diposisikan berdasarkan pola penyebaran bunyi yang bergerak secara radial. Titik ukur ditempatkan dari area terdekat dengan sumber bunyi hingga area terjauh baik di lantai bawah maupun lantai balkon.

Tabel 1. Tingkat kekerasan suara fungsi teater

\begin{tabular}{|c|c|c|}
\hline Titik & Jarak $(\mathrm{m})$ & Kekerasan Suara \\
\hline 1 & $5.81 \mathrm{~m}$ & $83.2 \mathrm{~dB}$ \\
\hline 2 & $10.43 \mathrm{~m}$ & $79.1 \mathrm{~dB}$ \\
\hline 3 & $15.6 \mathrm{~m}$ & $76.9 \mathrm{~dB}$ \\
\hline 4 & $21.37 \mathrm{~m}$ & $73.4 \mathrm{~dB}$ \\
\hline 5 & $10.16 \mathrm{~m}$ & $79.5 \mathrm{~dB}$ \\
\hline 6 & $14.3 \mathrm{~m}$ & $77.5 \mathrm{~dB}$ \\
\hline 7 & $6.2 \mathrm{~m}$ & $84.3 \mathrm{~dB}$ \\
\hline 8 & $9.4 \mathrm{~m}$ & $81.1 \mathrm{~dB}$ \\
\hline 9 & $18.3 \mathrm{~m}$ & $77.9 \mathrm{~dB}$ \\
\hline 10 & $27.8 \mathrm{~m}$ & $72.7 \mathrm{~dB}$ \\
\hline
\end{tabular}


The existential significance of ceremonial arches for the ...

Tabel 2. Tingkat kekerasan suara fungsi konser

\begin{tabular}{|c|c|c|}
\hline Titik & Jarak $(\mathrm{m})$ & Kekerasan Suara \\
\hline 1 & $5.81 \mathrm{~m}$ & $86 \mathrm{~dB}$ \\
\hline 2 & $10.43 \mathrm{~m}$ & $81.9 \mathrm{~dB}$ \\
\hline 3 & $15.6 \mathrm{~m}$ & $79.7 \mathrm{~dB}$ \\
\hline 4 & $21.37 \mathrm{~m}$ & $76.2 \mathrm{~dB}$ \\
\hline 5 & $10.16 \mathrm{~m}$ & $82.3 \mathrm{~dB}$ \\
\hline 6 & $14.3 \mathrm{~m}$ & $80.3 \mathrm{~dB}$ \\
\hline 7 & $6.2 \mathrm{~m}$ & $87.1 \mathrm{~dB}$ \\
\hline 8 & $9.4 \mathrm{~m}$ & $83.9 \mathrm{~dB}$ \\
\hline 9 & $18.3 \mathrm{~m}$ & $80.7 \mathrm{~dB}$ \\
\hline 10 & $27.8 \mathrm{~m}$ & $75.5 \mathrm{~dB}$ \\
\hline
\end{tabular}

Berdasarkan percobaan, tingkat kekerasan suara auditorium GKJ memenuhi syarat baik untuk fungsi teater maupun konser sehingga dari segi kekerasan suara GKJ dapat mengakomodasi keduanya dengan baik.

\subsubsection{PENDIFUSIAN ENERGI BUNYI}

Kemerataan pendifusian bunyi dideteksi dengan mengukur tingkat kekerasan bunyi saat ruang dalam kondisi kosong. Berdasarkan pengukuran terdapat perbedaan $11.6 \mathrm{~dB}$ antara bunyi terkeras dan bunyi terlemah sehingga dapat dikatakan bunyi tersebar tidak terlalu merata. Area belakang yang termasuk dalam area bayangan bunyi merupakan area dengan tingkat penyebaran bunyi terlemah.

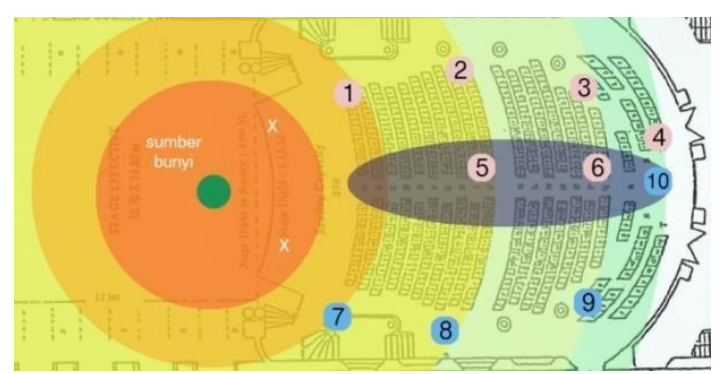

Figur 25. Tingkat penyebaran bunyi pada auditorium GKJ

\subsubsection{PENGENDALIAN WAKTU DENGUNG}

Waktu dengung optimum digitung pada frekuensi menengah yaitu pada frekuensi 500 Hz. Nilai optimum tersebutlah yang digunakan untuk membandingkan waktu dengung kedua fungsi yang dilaksanakan dalam GKJ. 


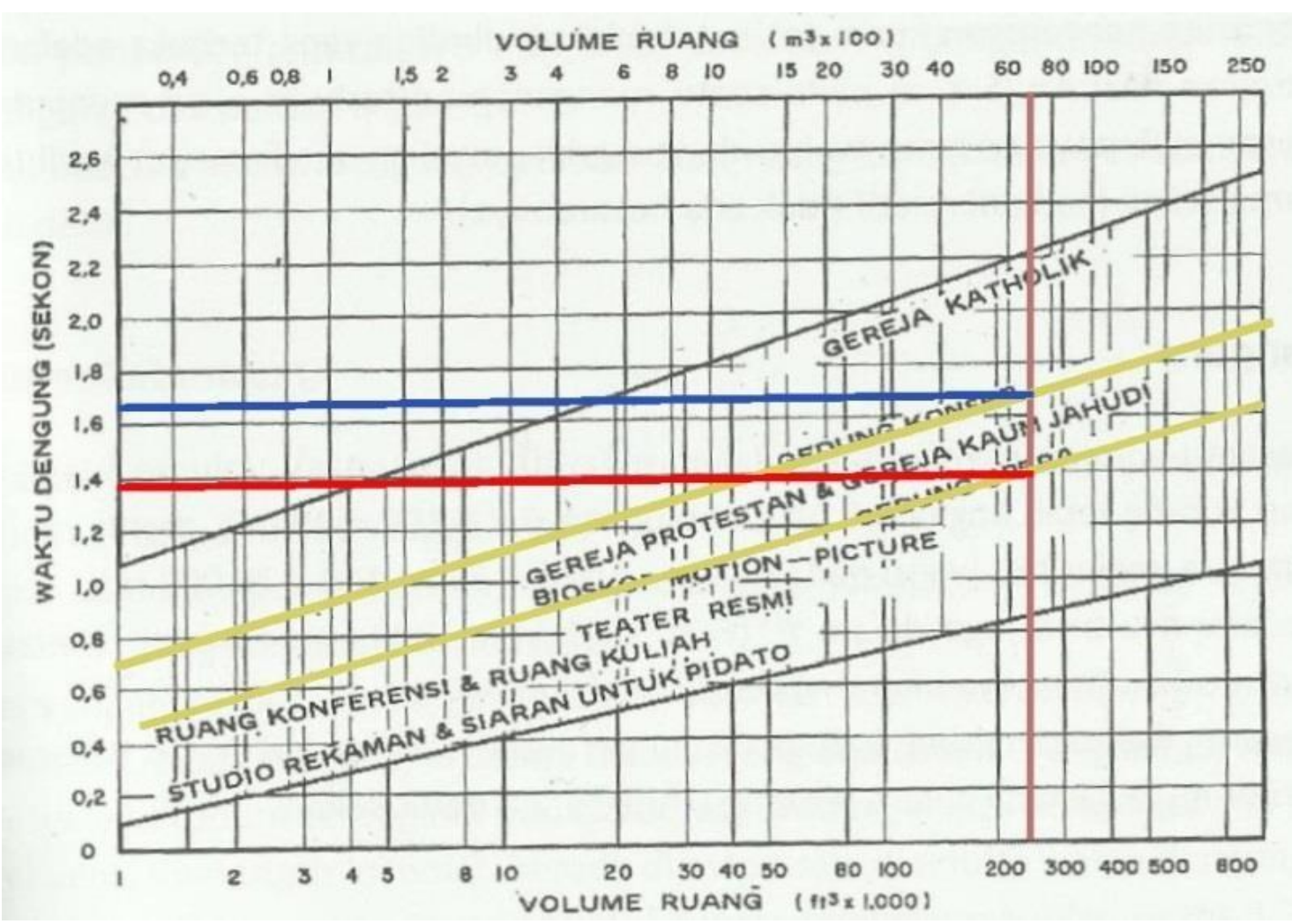

Figur 26. Grafik waktu dengung optimum

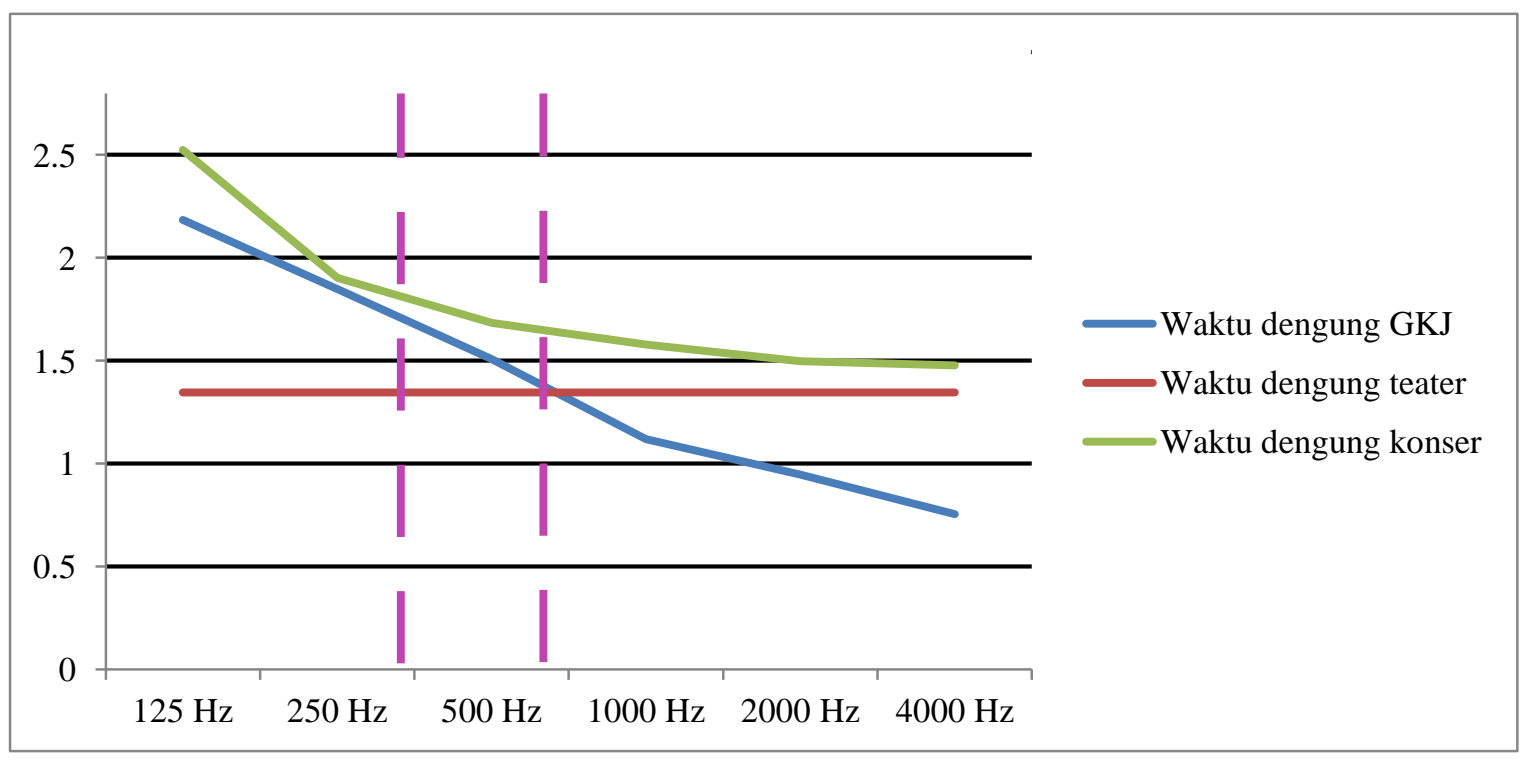

Figur 27. Grafik perbandingan waktu dengung

Dari grafik dapat diketahui bahwa waktu dengung GKJ berada pada area antara waktu dengung optimum fungsi teater dan konser sehingga membutuhkan pengkondisian ruang lebih lanjut.

Selain itu untuk melakukan pengujian terhadap kejelasan pendengaran pelafalan kata pada aktivitas teater dilakukan tes inteligibilitas suara dengan menggunakan 100 kata populer yang terdiri dari 10 kalimat tidak bersambung. 
The existential significance of ceremonial arches for the ...

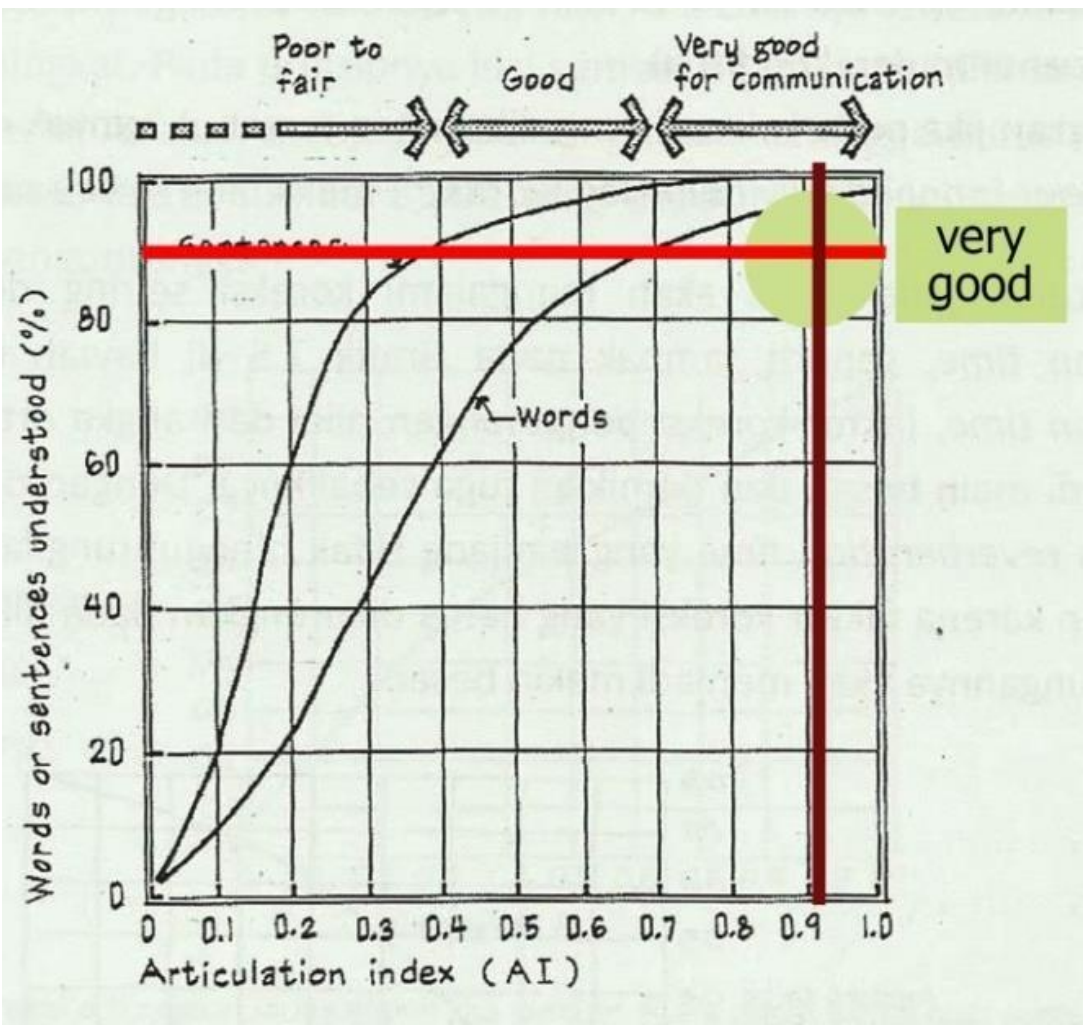

Figur 28. Grafik hasil tes inteligibilitas suara

Berdasarkan percobaan yang dilakukan, nilai inteligibilitas suara pada auditorium GKJ berada di atas angka 0.7 dimana hal ini membuktikan tingkat inteligibilitas suara GKJ termasuk sangat baik dan kata-kata dapat terdengar dengan jelas. Ketidakjelasan hanya ditemukan di area bayangan bunyi yang berada pada baris belakang penonton baik penonton lantai bawah maupun lantai balkon. Akan tetapi ketidakjelasan tersebut masih dapat ditoleransi.

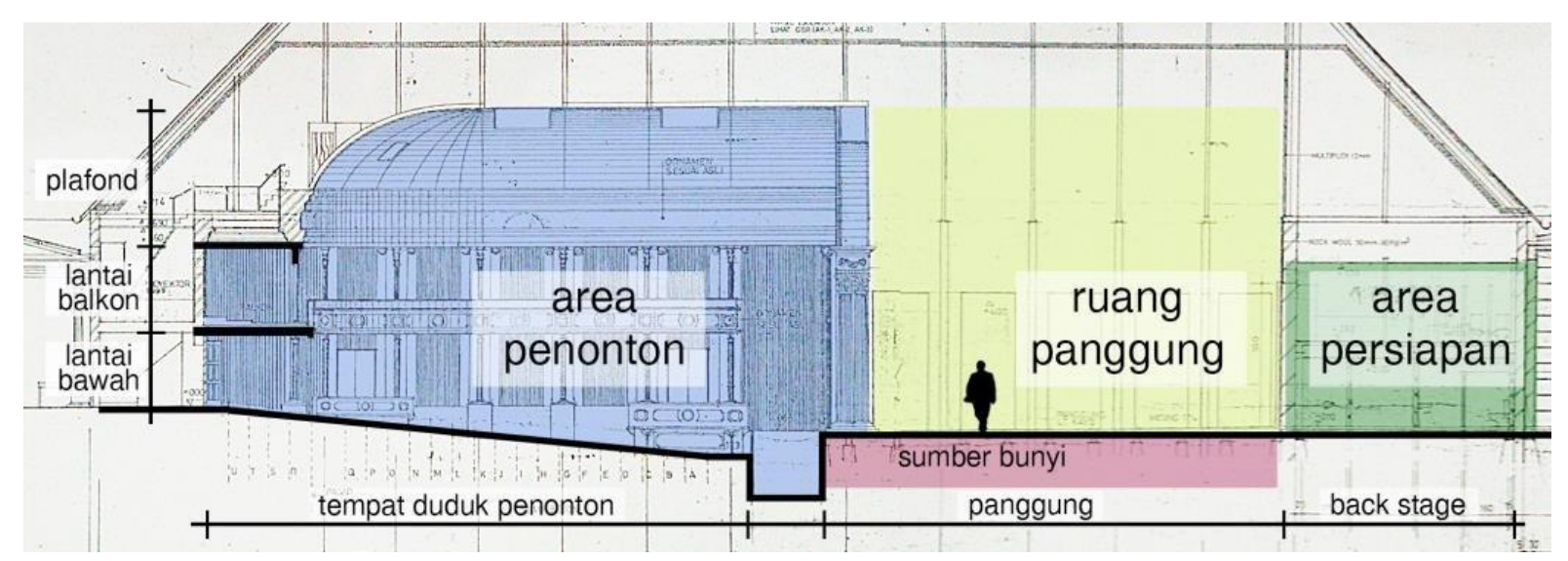

Figur 29. Ruang panggung yang besar

Ruang panggung yang besar mengakibatkan timbulnya efek couple space yang membuat waktu dengung di belakang panggung lebih besar dari waktu dengung di depan panggung. acoustical shell pada panggung sangat disarankan. Acoustical shell disusun dengan denah berbentuk lengkung parabolik agar bunyi dapat dipantulkan dengan maksimal ke arah penonton dengan arah menyebar. Selain itu pengaturan posisi kanopi acoustical shell 
dengan kemiringan $40^{\circ}$ dari gari juga dapat memaksimalkan arah pantulan bunyi menuju area yang merupakan area bayangan bunyi.

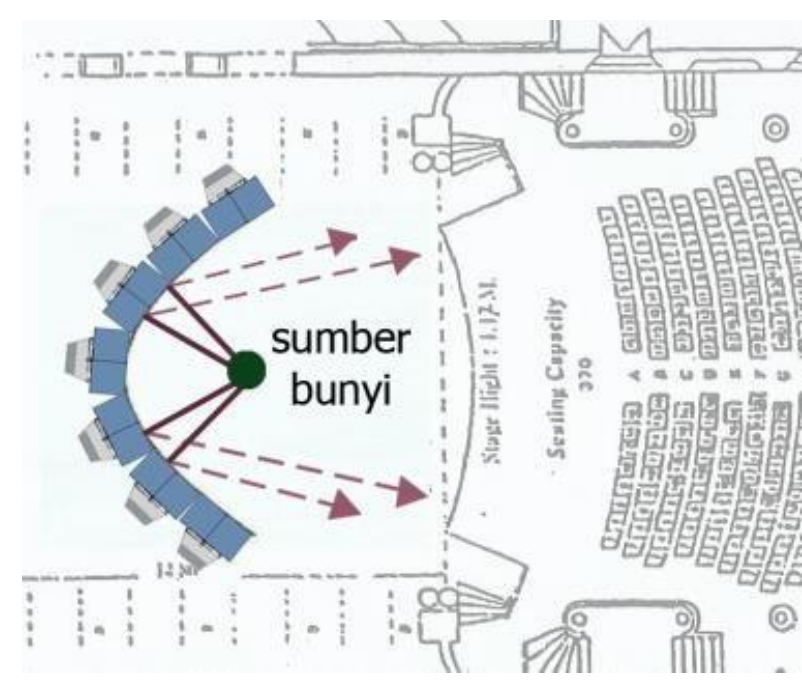

Figur 30. Penempatan acoustical shell di panggung

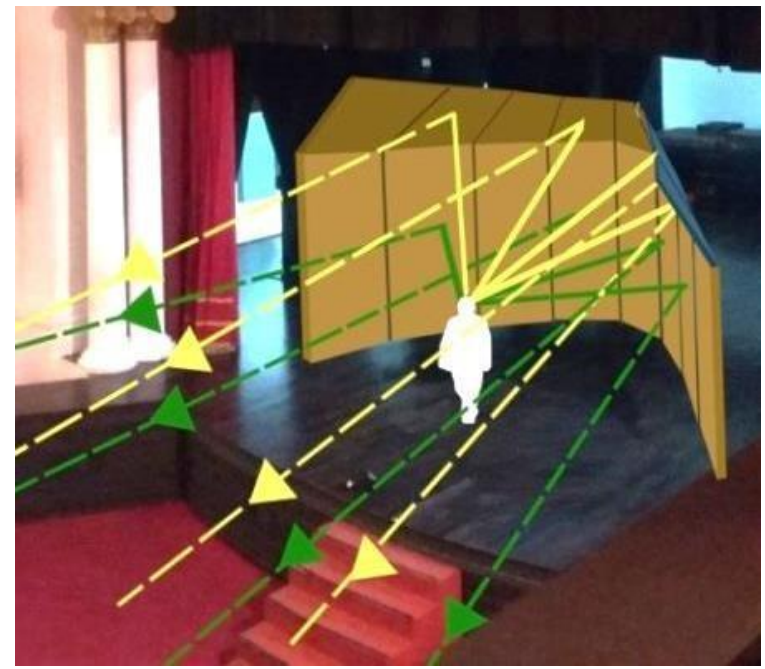

Figur 31. Pemantulan bunyi pada acoustical Shell

Acoustical shell akan menggunakan dua jenis material berbeda pada sisi depan dan belakang. Sisi depan yang menghadap penonton akan dilapis plywood 20mm untuk memaksimalkan pemantulan bunyi sedangkan sisi belakang akan menggunakan acoustic foam bergelombang untuk memaksimalkan penyerapan bunyi.

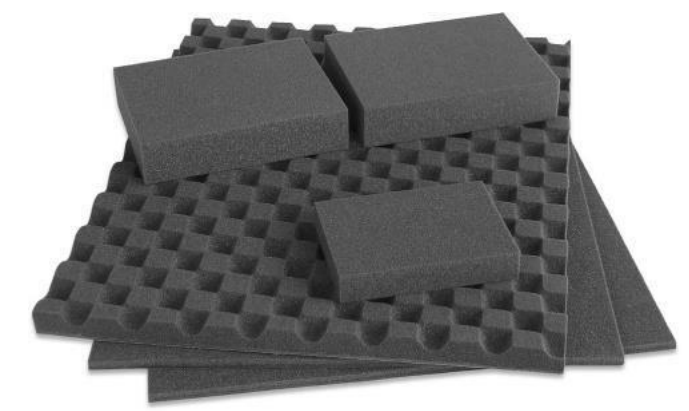

Figur 32. Acoustic foam bergelombang

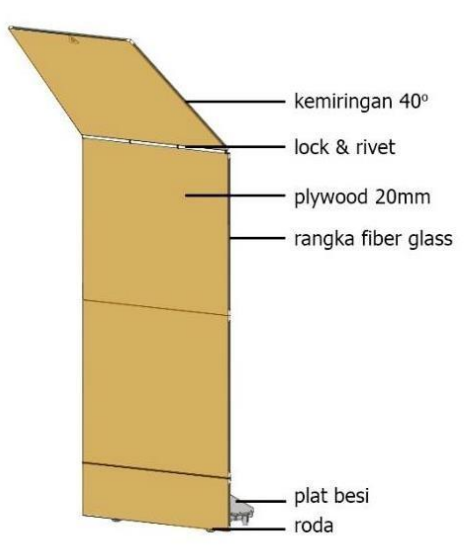

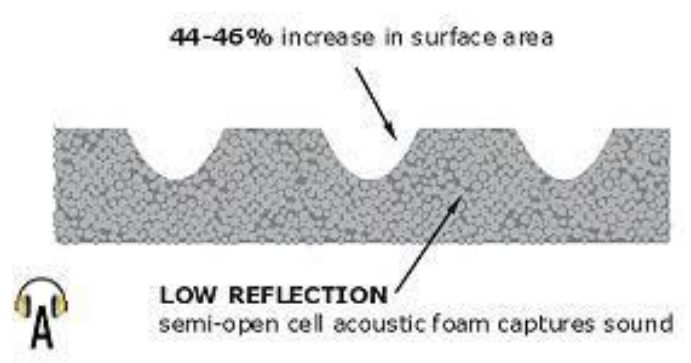

Figur 33. Potongan acoustic foam

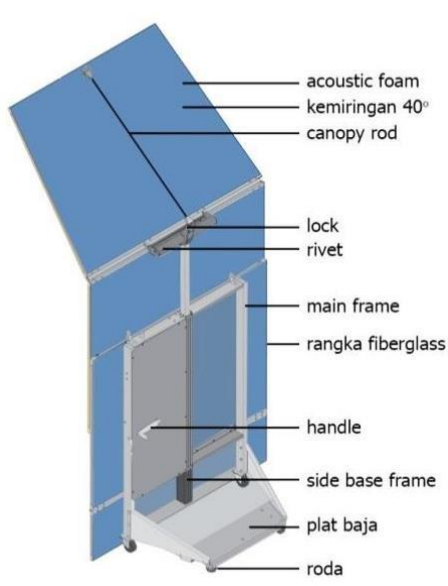


The existential significance of ceremonial arches for the ...

Konstruksi acoustic shell akan menggunakan fiber glass yang ringan namun bersifat lembam. Material tambahan yang bersifat movable ini hanya akan digunakan untuk kegiatan konser musik dalam kaitanya dengan kebutuhan dan nilai fungsional aktivitas tersebut.

\subsubsection{CACAT AKUSTIK}

Cacat akustik yang terjadi pada auditorium GKJ adalah bayangan bunyi yaitu pada barisan belakang tempat duduk penonton baik di lantai bawah maupun lantai balkon. Hal ini disebabkan oleh perbedaan ketinggian plafond yang cukup jauh sehingga mengakibatkan pantulan suara yang curam.

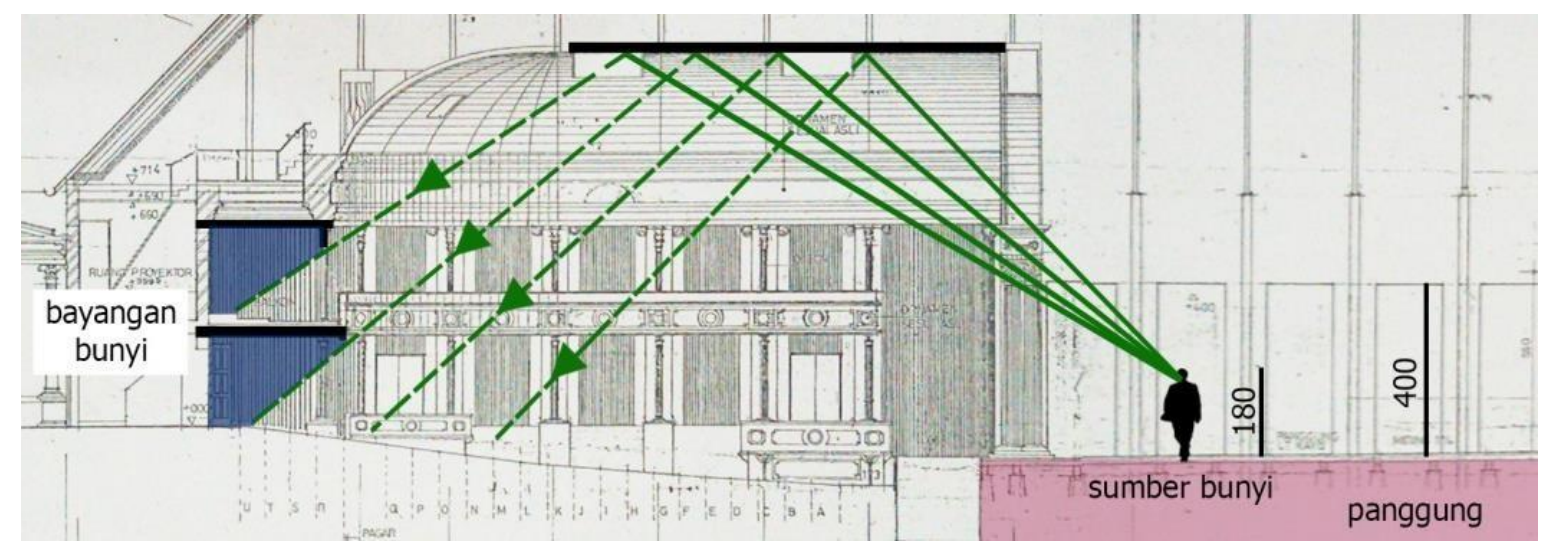

Figur 36. Area bayangan bunyi pada auditorium GKJ

Permasalahan tersebut dapat ditangani dengan peletakkan acoustical shell dengan bidang kanopi atas didesain dengan kemiringan $40^{\circ}$ agar dapat secara maksimal memantulkan bunyi ke arah area bayangan bunyi.

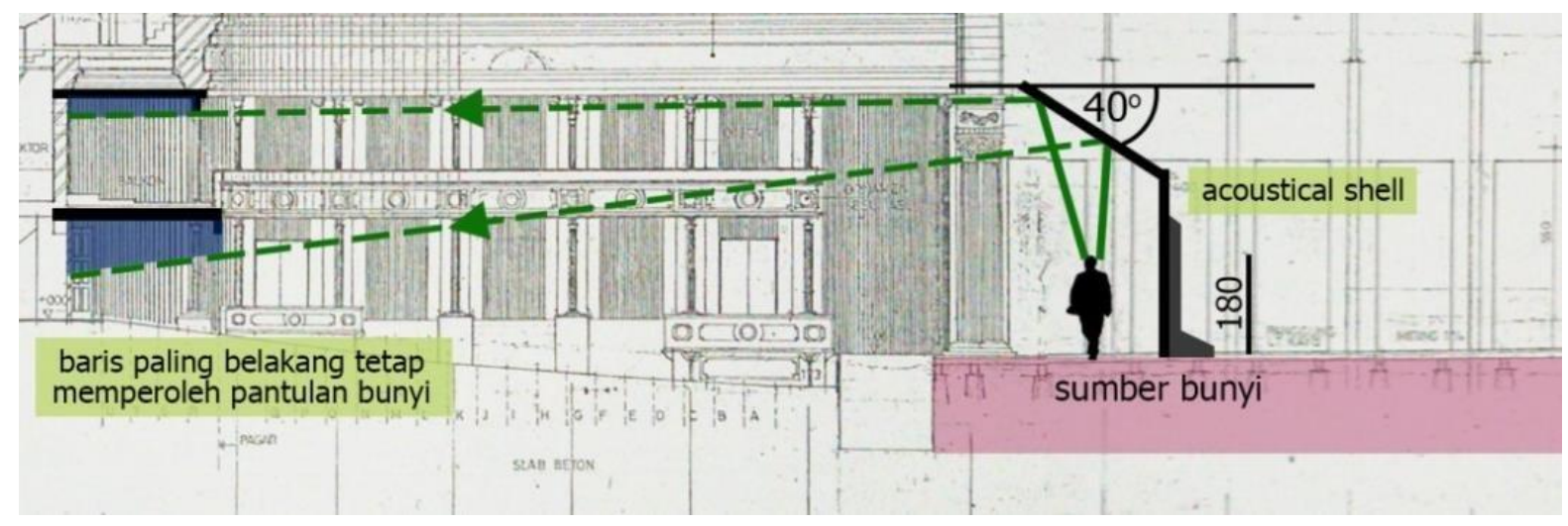

Figur 37. Pemantulan bunyi pada acoustical shell

\subsubsection{PENGENDALIAN BISING}

Pengendalian bising auditorium GKJ yang diapit oleh dua jalan raya diatasi melalui penempatan bangunan di area sudut tapak. Selain itu peletakkan plaza di area depan serta penambahan pagar serta vegetasi turut memberikan kontribusi pengurangan kebisingan hingga total $12 \mathrm{~dB}$. 


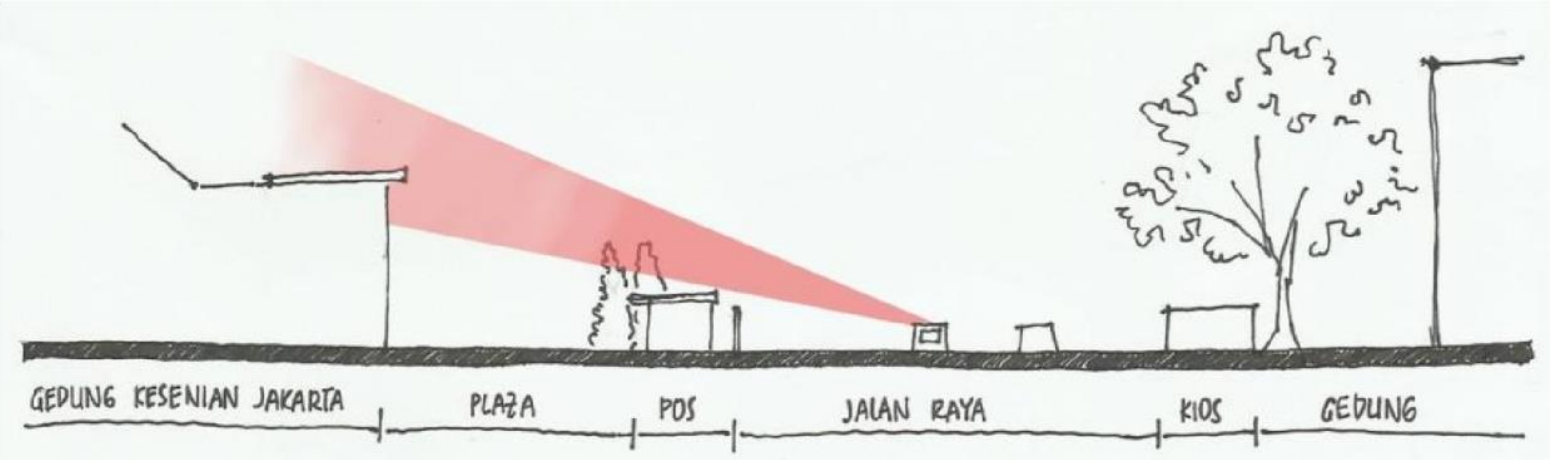

Figur 38. Bayangan bunyi akibat pagar GKJ

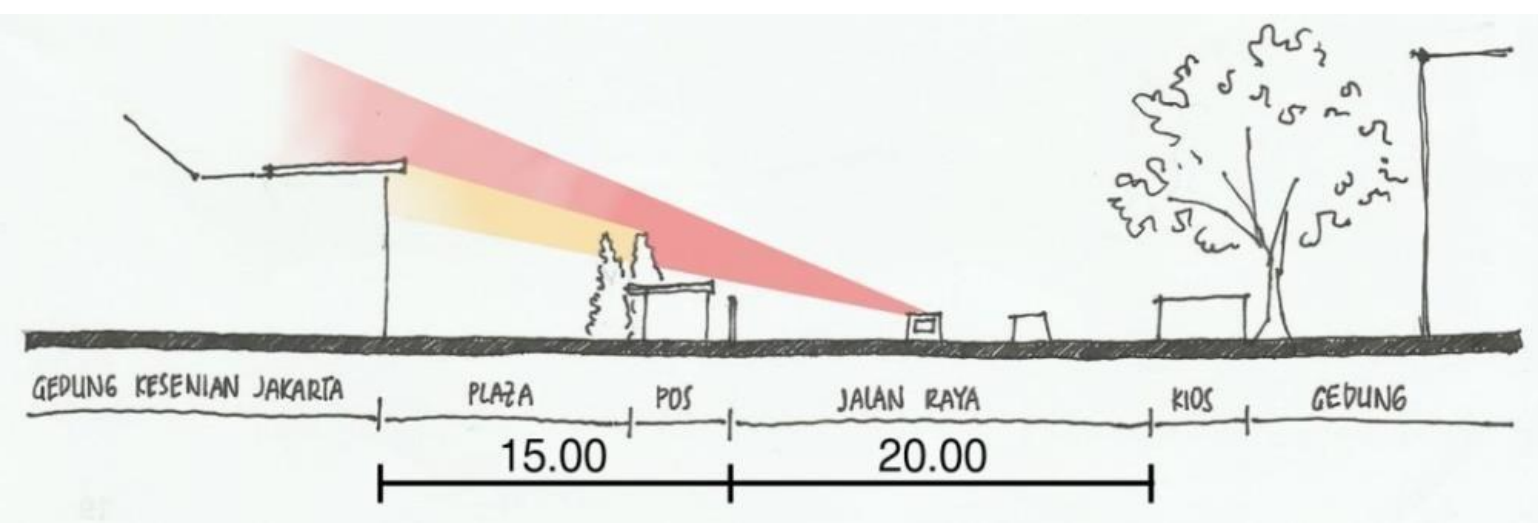

Figur 39. Bayangan bunyi akibat pagar dan vegetasi GKJ

\section{KESIMPULAN}

\subsection{KESIMPULAN}

\subsubsection{PENGARUH BENTUK RUANG TERHADAP FUNGSI TEATER DAN KONSER}

Bentuk ruang auditorium GKJ sangat berperan dalam kaitannya dengan volume ruang serta fenomena-fenomena akustik. Dari segi volume ruang, berdasarkan jumlah kapasitas penonton, volume ruang/tempat duduk penonton GKJ $7052 \mathrm{~m}^{3}$ terlalu besar, dimana hal ini menyebabkan penyaluran energi bunyi dari sumber bunyi menuju penonton menjadi kurang efektif.

Sedangkan dari segi dimensi, ukuran-ukuran yang diterapkan dalam Gedung Kesenian Jakarta sudah memenuhi kriteria yang berlaku baik untuk aktivitas teater maupun aktivitas konser.

\subsubsection{PENGARUH MATERIAL TERHADAP FUNGSI TEATER DAN KONSER}

Fungsi utama material pada ruang dalam auditorium adalah memaksimalkan kualitas suara sehingga dapat mencapai kelayakan akustik ruang yang ideal. Gedung Kesenian Jakarta memanfaatkan material pemantul, material penyerap, dan material pendifusi suara pada bagian ruang yang berbeda. Pengkombinasian material tersebut sudah cukup baik untuk memaksimalkan penyerapan dan pemantulan bunyi sesuai posisinya demi kenyamanan penonton baik dalam menikmati pertunjukan teater maupun konser. 


\subsubsection{KELAYAKAN AKUSTIK RUANG}

\section{Fungsi teater}

(1) Tingkat kekerasan bunyi

Tingkat kekerasan bunyi auditorium GKJ berada pada 72.7-83.2 dB dimana angka tersebut masih termasuk dalam batas nyaman untuk aktivitas teater.

(2) Difusi bunyi

Perbedaan tingkat kekerasan bunyi sebesar $11.6 \mathrm{~dB}$ di area yang tersebar baik di area yang dekat dengan sumber bunyi maupun area terjauh membuktikan kurangnya kemerataan penyebaran bunyi dalam auditorium GKJ.

(3) Waktu dengung

Berdasarkan perhitungan, waktu dengung GKJ adalah 1.52 dimana angka tersebut terlalu panjang untuk aktivitas teater yang seharusnya memiliki waktu dengung 1.35 untuk ruang an bervolume $7052 \mathrm{~m}^{3}$.

(4) Cacat akustik

Cacat akustik yang terjadi adalah bayangan bunyi yang ditemukan pada baris terakhir tempat duduk penonton baik di lantai bawah maupun lantai balkon.

(5) Pengendalian bising

Pengendalian bising baik bising dari luar maupun bising dari dalam pada auditorium GKJ sudah optimum.

\section{Fungsi konser}

(1) Tingkat kekerasan bunyi

Tingkat kekerasan bunyi auditorium GKJ untuk aktivitas konser musik berada pada 75.5-86 dB. Angka tersebut masih termasuk dalam batas persyaratan kenyamanan aktivitas konser yaitu antara 70-90 dB.

(2) Difusi bunyi

Perbedaan tingkat kekerasan bunyi sebesar $11.6 \mathrm{~dB}$ di area membuktikan kurangnya kemerataan penyebaran bunyi dalam auditorium GKJ.

(3) Waktu dengung

Waktu dengung GKJ berdasarkan perhitungan manual yang dilakukan adalah 1.52 detik. Angka tersebut masih berada di bawah nilai waktu dengung optimum GKJ untuk fungsi konser yaitu 1.685 detik.

(4) Cacat akustik

Cacat akustik yang terjadi adalah bayangan bunyi yang ditemukan pada baris terakhir tempat duduk penonton baik di lantai bawah maupun lantai balkon.

(5) Pengendalian bising

Pengendalian bising baik bising dari luar maupun bising dari dalam pada auditorium GKJ sudah optimum.

Berdasarkan hasil perhitungan dan analisa yang telah dilakukan, terutama dalam kaitannya dengan waktu dengung, dapat diketahui bahwa pada dasarnya auditorium Gedung Kesenian Jakarta lebih cocok digunakan sebagai ruang konser dibandingkan dengan ruang teater. Hal ini dibuktikan melalui grafik perhitungan waktu dengung yang cenderung menurun seiring bertambahnya frekuensi. Oleh karena itu dapat disimpulkan bahwa terjadi kesalahan pemanfaatan ruang dalam auditorium Gedung Kesenian Jakarta. 


\subsection{SARAN}

Terdapat dua hal penting yang belum terselesaikan dalam perancangan auditorium GKJ yaitu waktu dengung dan cacat akustik. Beberapa upaya yang mudah dilakukan dengan memanfaatkan penggunaan material yang ada antara lain dengan melakukan penambahan tirai sebagai material penyerap bunyi pada aktivitas teater untuk memperkecil nilai waktu dengung dan memaksimalkan material pemantul berupa panggung movable pada aktivitas konser untuk memperpanjang nilai waktu dengung.

Namun terdapat saran yang efektif untuk dapat mengatasi permasalahan di atas yaitu dengan menggunakan acoustical shell yang diposisikan membentuk denah lengkung parabolik untuk menyebarkan bunyi ke segala arah. Selain itu penggunaan material plywood pada sisi depan dan acoustic foam pada sisi belakang turut menyeimbangkan perbedaan waktu dengung di bagian depan dan belakang panggung. Untuk mengatasi permasalahan bayangan bunyi, kanopi acoustical shell diatur kemiringannya sebesar $40^{\circ}$ dari bidang horizontal untuk memantulkan bunyi ke area bayangan bunyi baik di lantai bawah maupun lantai balkon.

\subsection{PENUTUP}

Pada akhirnya diharapkan makalah penelitian ini dapat memberikan gambaran mengenai kualitas akustik Gedung Kesenian Jakarta yang menampung dua fungsi spesifik sekaligus. Semoga makalah ini dapat berguna serta menambah wawasan pihak-pihak yang membacanya serta berguna bagi proses pembelajaran yang akan datang.

Namun makalah penelitian ini merupakan produk yang belum sempurna. Oleh karena itu diharapkan pembaca dapat memberikan kritik dan saran yang membangun untuk menjadi masukan yang berguna.

\section{DAFTAR PUSTAKA}

Bahiuddin, Irfan. (2016). Material Absorbsi. [Online]. Tersedia: http://irfannote.blogspot.co.id/2014/01/ada-empat-tipe-bahan-atau-material.html. [9 April 2016].

Ching, D.K. (2008). Arsitektur Bentuk, Ruang, dan Tatanan. Jakarta: Erlangga

Doelle, Leslie L. (1993). Akustik Lingkungan. Jakarta: Erlangga

Egan, M. David. (1988). Architectural Acoustics. New York: McGraw-Hill Book Company

Kanthong, Antariksa. (2016). Arsitektur dan Dimensi Ruang. [Online]. Tersedia: http://antariksaarticle.blogspot.co.id/2009/03/arsitektur-dan-dimensi-ruang.html. [8 April 2016].

Metha, M., J. Johnson \& J. Rocafort. (1999). Architectural Acoustics: Principles and Design. New Hersey: Prentice Hall.

Moleong, Lexy J. (1999). Metodologi Penelitian Kualitatif. Bandung: PT Remaja Rosdakarya.

Moore, J. E. Friba. (1978). Design for Good Acoustics and Noise Control. London: The Macmillan Press Ltd.

NN. (2016). Sound Absorption Coefficients. [Online]. Tersedia: http://www.acousticalsurfaces.com/acoustic_IOI/101_13.html/. [28 Maret 2016].

Palladio, Andrea. (1997). The Four Books on Architecture. Massachusetts: MIT Press.

Parkin, P. H. (1969). Acoustics, Noise and Buildings. London: Faber and Faber Ltd. 
The existential significance of ceremonial arches for the ...

Sarwono, Joko. (2016). Dunia Akustik. [Online]. Tersedia: http://duniaakustik.wordpress.com. [6 April 2016].

Strong, Judith. (2010). Theatre Buildings a Design Guide. New York: Routledge.

Sudibjo, Slamet. (1987). Evaluasi Purna Huni Dasar Teori dan Penerapannya. Yogyakarta: PDIILIPI.

Sutanto, Handoko. (2015). Prinsip-Prinsip Akustik dalam Arsitektur. Yogyakarta: Kanisius

Wibisono, Satrio. (2016). Tekstur. [Online]. Tersedia: http://satriowibisono.blogspot.co.id/2008/09/tekstur.html. [9 April 2016]. 